\begin{tabular}{|c|c|}
\hline Title & Regional forest biomass estimation using ICESat/GLA S spaceborne LiDA R over Borneo \\
\hline Author(s) & Hay ashi, Masato; Saigusa, Nobuko; Y amagata, Y oshiki; Hirano, Takashi \\
\hline Citation & $\begin{array}{l}\text { Carbon management, 6(1-2), 19-33 } \\
\text { https://doi.org/10.1080/17583004.2015.1066638 }\end{array}$ \\
\hline Issue Date & 2015-03-04 \\
\hline Doc URL & http:/hdl.handle.net/2115/60762 \\
\hline Rights & $\begin{array}{l}\text { This is an A ccepted Manuscript of an article published by Taylor \& Francis in Carbon Management on } 4 \text { Mar 2015, } \\
\text { available online: http:/wwww.tandfonline.com/10.1080/17583004.2015.1066638. }\end{array}$ \\
\hline Type & article (author version) \\
\hline File Information & 71377(hirano) .pdf \\
\hline
\end{tabular}

Instructions for use 


\title{
Regional forest biomass estimation using ICESat/GLAS spaceborne LiDAR over Borneo
}

\begin{abstract}
Background: We aimed to clarify the potential of spaceborne light detection and ranging (LiDAR) to meet the increased demand for large-scale monitoring of forest resources.

Results: We developed empirical models to estimate aboveground biomass (AGB) and canopy height in Borneo from Ice, Cloud, and land Elevation Satellite (ICESat)/Geosciences Laser Altimeter System (GLAS) data, and obtained root-mean-square errors of $38.7 \mathrm{Mg} \mathrm{ha}^{-1}$ and $4.0 \mathrm{~m}$, respectively. GLAS-estimated AGB averaged $191.8 \mathrm{Mg} \mathrm{ha}^{-1}$. From 2004 to 2007, AGB decreased by an average of $33.1 \mathrm{Mg} \mathrm{ha}^{-1}$, and the rate of forest loss was $2.4 \%$ year $^{-1}$. The total AGB in Borneo was estimated as $10.34 \mathrm{Gt}$.

Conclusions: The results demonstrate the potential of spaceborne LiDAR for monitoring forest resources, and its potential to play an important role in Reducing Emissions from Deforestation and Forest Degradation (REDD+) implementations.
\end{abstract}

Keywords: aboveground biomass, Borneo, forests, LiDAR, satellite remote sensing

\section{Introduction}

Demands for remote-sensing technology have increased in response to a growing need to estimate forest resources efficiently and accurately over large areas. Two perspectives are driving this demand: the scientific perspective, in which a key goal is to reduce uncertainties in descriptions of the global carbon cycle, and the political perspective, in which a key goal is to find ways to mitigate global warming. Forests are important from both perspectives: because 
they sequester large quantities of atmospheric carbon, they both serve as important components of the global carbon cycle and mitigate global warming. However, deforestation is a growing concern because it can interfere with both roles, and in an attempt to solve this problem, participants in the United Nations Framework Convention on Climate Change (UNFCCC) have developed a scheme called Reducing Emissions from Deforestation and Forest Degradation (REDD+; http://www.un-redd.org/). REDD+ relies on a forest monitoring system that can provide accurate estimates of forest carbon stocks and their changes at a national level, and remote-sensing technology is required to meet this need [1-3].

In efforts to estimate forest carbon stocks using remote-sensing technology, estimating the aboveground biomass (AGB) is usually adopted as the initial goal. Biomass represents the dry weight of living organisms, and in forests, most of this is stored in plants. AGB can be simply converted into a measure of the aboveground forest carbon stocks (i.e., excluding the root system) by multiplying AGB by the carbon fraction, which represents the proportion of the biomass accounted for by carbon; the IPCC default value for this fraction is 0.47 [4].

The number of studies of forest biomass estimation using remote-sensing technologies has been increasing rapidly in recent years [5]. In particular, optical remote-sensing has a long history, and many studies have been conducted on the use of optical technologies for forest biomass estimation [5-7], even though this approach has limitations. For example, spectral characteristics are influenced not only by forest biomass, but also by several factors such as slope angle, tree species and density, and soil properties; therefore, it can be difficult to directly associate forest spectral data with forest biomass over large areas under a range of forest conditions [8]. Furthermore, signal saturation can occur in high-biomass forests, leading to 
underestimates of AGB [7]. Although synthetic aperture radar (SAR) has been adopted for forest biomass estimation in recent studies, it also faces the problem of signal saturation [9].

Spaceborne light detection and ranging (LiDAR) is an active optical sensor that potentially overcomes the signal saturation problem in high-biomass forests, and it can therefore be used for accurate estimates of forest AGB [10-11]. Before the Geoscience Laser Altimeter System (GLAS) aboard NASA's Ice Cloud and land Elevation Satellite (ICESat) ceased operation in late 2009, it was the only spaceborne LiDAR system capable of measuring land surfaces [12, 13]. Its principal objective was to monitor polar ice sheets, but it has also been used for observations of forest characteristics such as canopy height and AGB [14]. GLAS observes the profile of the laser's return pulses as a waveform, which can be analyzed to estimate AGB.

Previous studies of forest AGB estimation from GLAS waveforms can be categorized into two main approaches. The first approach estimates canopy height from the GLAS waveform, then converts the height into AGB by using allometric models [e.g., 15-17]. There are several methods to estimate canopy height from GLAS data. However, the two analytical steps in this process each have inherent estimation errors (errors in canopy height estimation and errors in the allometric model), so this approach may decrease the overall estimation accuracy. The second approach estimates AGB directly from the GLAS waveform by means of multiple-regression analysis [e.g., 18-20]. Although this approach is expected to provide higher accuracy, the estimation model developed by this approach may be specific to the area for which it was developed, and may therefore be inapplicable to different areas. To implement this approach, some studies have adopted machine-learning algorithms (e.g., neural networks) to estimate AGB from a GLAS waveform, instead of requiring a multiple-regression analysis [21, 22]. 
In this study, we aimed to determine the potential of spaceborne LiDAR for large-scale estimation of forest AGB. We adopted the second approach to accurately estimate AGB directly from the GLAS waveform. For our study, we chose Borneo, where the forested area has decreased rapidly in recent years [23, 24], and we focused on the context of REDD+. A previous study used GLAS data to estimate forest AGB in Borneo [25]; however, it targeted only peat swamp forests in a limited area. In this study, we aimed to assess all of Borneo's forest resources as accurately as possible, and to do so, we developed an AGB estimation model based on field-measured data.

\section{Methods}

\subsection{Study area}

Borneo is the third-largest island in the world $\left(743,300 \mathrm{~km}^{2}\right)$, and is occupied by three countries: Indonesia, Malaysia, and Brunei Darussalam. Borneo lies between $7^{\circ} \mathrm{N}$ and $4^{\circ} \mathrm{S}$, and has a tropical rainforest climate with high temperature and relative humidity. The name Borneo has been adopted in Malaysia and Brunei Darussalam, but the Indonesian name is Kalimantan; for simplicity, we will refer to the island as Borneo in this paper. Borneo has the largest area of tropical forest in Southeast Asia. Much of its natural forest consists of mixed dipterocarp forests, but peat swamp forests and mangrove forests are also common. These forests are rich in biodiversity, and provide habitat for many rare animals and plants.

The area of forests in Borneo has been rapidly decreasing in recent years. Miettinen et al. reported that Borneo lost $5 \times 10^{6}$ ha of forested area between 2000 and 2010, which corresponded to $12.0 \%$ of the island's total forested area [26]. The primary factors responsible 
for these huge losses were logging, fire, and conversion to plantations [27]. Because of this background, Borneo is one of the most important target areas for meeting REDD+ targets.

\subsection{GLAS data}

GLAS irradiated the Earth's surface using laser light with a wavelength of 1,064 nm, and it recorded the time-varying intensity of the return signal as a waveform. The GLAS footprint is elliptical with a 60-m nominal diameter, but the size varied according to the observation period. The footprints were spaced at intervals of approximately $172 \mathrm{~m}$ on the ground along ICESat's orbital track [13]. ICESat has a near-polar orbit, with a $94^{\circ}$ inclination, and it covered latitudes between $86^{\circ} \mathrm{N}$ and $86^{\circ} \mathrm{S}$ globally.

We used two release-33 GLAS products: GLA01 (L1A Global Altimetry Data) and GLA14 (L2 Global Land Surface Altimetry Data). The GLAS data was obtained during 19 operational campaigns between 2003 and 2009, and we collected data from all of the campaigns that observed Borneo. We used ArcGIS 10.1 (ESRI Inc., Redlands, CA, USA) to process the data.

Part of the collected GLAS data was likely to be unsuitable for analysis, as is the case for any remote-sensing dataset, so we performed three data-screening steps. For the first step, we eliminated data from the L2C and L2F campaigns, when the geolocation accuracy of the GLAS footprints was low [28]. For the second step, we excluded data affected by a high degree of cloud cover, and we performed two procedures for the purpose. First, we used the GLA14 product to select cloud-free data (i_FRir_qaFlag $=15)$ and saturation-free data (i_satNdx $=0$ ). We then compared the GLAS-measured ground elevation with data from the Shuttle Radar Topography Mission (SRTM; http://www2.jpl.nasa.gov/srtm/) in an attempt to completely exclude data that 
were seriously affected by cloud cover. The SRTM elevation dataset was produced using SAR aboard Space Shuttle Endeavour, and covers the world with 90-m resolution. In vegetated regions, the SRTM elevation represents values near the canopy top (not the ground), because the SAR microwaves are usually scattered at the canopy level. Nevertheless, the SRTM data can be used to identify GLAS data obscured by clouds in the upper sky. In a histogram of the differences between the GLAS-measured elevation and the SRTM-measured elevation over Borneo, almost all of the values were near $0 \mathrm{~m}$ (i.e., no differences), but there was a small group of values greater than $80 \mathrm{~m}$ that we considered to represent data with cloud cover. Therefore, we excluded GLAS data that indicated an elevation of more than $80 \mathrm{~m}$ above the corresponding SRTM data on the assumption that these data represented cloud covered data. For the third step of the data-screening, we excluded data with a noisy waveform by rejecting waveform data with a signal-to-noise ratio (SNR) of $<10$. We chose 10 as the SNR threshold because Hayashi et al. found that canopy height estimation using GLAS data with SNR <10 had remarkably low accuracy [29]. We calculated SNR as the ratio of the mean power of the return pulse to the standard deviation of the background noise [30].

We also used the Global Land Cover 2000 (GLC2000; http://bioval.jrc.ec.europa.eu/products/glc2000/glc2000.php) map to extract GLAS data obtained only from forested areas. The GLC2000 map is a land-cover type map produced from SPOT/Vegetation imagery acquired during 1999 and 2000, and it covers the world with a 1-km resolution. Here, it was necessary to recognize that the time difference between the GLC2000 date and the GLAS observation date might lead to errors in the extraction, as we will describe in detail in Section 2.5. The GLC2000 product for Southeast Asia includes 17 land cover classes, 
from which we extracted eight classes associated with tree or shrub cover that could be used to represent forested areas.

As a result of these screening procedures, extraction of the forested area provided 127,862 GLAS data points that were suitable for analysis (Figure 1). The GLAS footprints were located linearly along ICESat's orbital track, and the ellipsoidal footprints of approximately $60 \mathrm{~m}$ are spaced about $172 \mathrm{~m}$ apart [13].

We developed an AGB estimation model using some of the GLAS waveform parameters. Table 1 summarizes the 14 candidate GLAS waveform parameters used for the model development. We selected the best of these 14 parameters (i.e., the ones that produced the best fit to the ground-referenced data) using multiple regression. The waveform extent (WE) is the most basic parameter, and it is associated with the canopy height. The relative heights (RH1O to RH100) are frequently used for AGB estimation. In particular, RH5O is called HOME (Height Of Median Energy), and Drake et al. found that HOME was strongly correlated with forest biomass when using airborne LiDAR data [31]. Guo et al. found that the $R H 75$ parameter (the relative height of 75\% energy return) of GLAS data was strongly correlated with AGB [20]. To calculate the relative heights, the peak that represents the ground return must be identified in the GLAS waveform. To do so, we used the Gaussian decomposition information in GLA14, and we identified the larger of the lowest two peaks as the ground peak [32]. The other three parameters were used to correct for the broadening of the GLAS waveform that occurs in sloping terrain. The leading and trailing edges were introduced by Lefsky et al. [33], and the lead10 and trail10 parameters ( $L 10$ and $T 10$ in Table 1) were introduced by Lefsky [34]. Both parameters describe the edge extents of the GLAS waveform, and they become larger as the slope increases. The 
terrain index (TI) was introduced by Lefsky et al. [15], and this is calculated from digital elevation model (DEM) data, not from the GLAS waveform. Here, we used the SRTM DEM data. Although the SRTM represents the canopy elevation rather than the ground elevation, it could nonetheless be used to estimate $T I$ because the canopy slope was influenced by the ground slope in many cases. We used these parameters shown in Table 2 for the development of AGB estimation model.

\subsection{Field data}

We collected field-measured data as ground-referenced data to validate the GLAS data, thereby allowing us to develop an AGB estimation model from the GLAS data. The field measurements were conducted at the five sites shown in Figure 2; Table 2 provides details of each site. We estimated AGB from 2013 to 2014 in 37 plots that coincided with the GLAS footprints. Those plots comprised four forest types. Peat swamp forest develops heavy peat accumulation as a result of waterlogging during the rainy season, which prevents dead leaves and wood from fully decomposing. Many of the region's peat swamp forests have been drained and cut for conversion into agricultural land in recent years [35-37]. Secondary forest becomes established as a result of secondary succession after a disturbance, and the secondary forests at two measurement sites were mostly evergreen broadleaved forests with Macaranga as the dominant genus. The forest reserve at Ulu Tungud mostly retained virgin vegetation, but it has sustained some selection logging in the past; it is a dipterocarp-dominated evergreen broadleaved forest. Oil palm plantations are artificial forests established to allow harvesting of palm oil, and have rapidly expanded in Borneo. The forest types in which we conducted the field 
measurements correspond to evergreen broadleaved forest, mosaic forest, and swamp forest in the GLC2000 category. These categories cover $86.1 \%$ of the forested area in Borneo. Although there were other forest categories, such as mangrove swamp, the field measurements nonetheless covered the main forest types in Borneo.

We measured AGB using the time-efficient Bitterlich sampling technique [e.g., 38], which is also known as variable-radius sampling. This technique is a plotless sampling method that does not establish a fixed-size plot for measurements. Instead, it measures a sample of the trees under the assumption of a homogeneous forest. The advantage of this technique is that it combines acceptable measurement accuracy with a remarkably shorter measurement time compared to measuring every tree in a sample plot; it was possible to finish the measurements at each site in about 30 minutes. This technique estimates the total basal area per hectare, from which AGB can be estimated by using an expansion factor and an allometric model, as described in the following paragraphs. First, we identified the center of each GLAS footprint using a GPS device (GPSmap 62s; Garmin Ltd., Schaffhausen, Switzerland). The geolocation accuracy of this device ranged from 3 to $10 \mathrm{~m}$ after time averaging, and the accuracy was acceptable (i.e., the positional error was much smaller than the GLAS footprint size of $60 \mathrm{~m}$ ). Next, we established a measurement position at the center of the footprint, and from this position, we used a Criterion RD1000 electric relascope (Laser Technology, Inc., Centennial, CO, USA) to count the number of trees whose stems at breast height (1.3 $\mathrm{m}$ above the ground) were wider than a fixed viewing angle. The total basal area per hectare can be estimated by multiplying the number of counted trees by a basal area factor (BAF), which can be calculated from the viewing angle. As the viewing angle should be chosen according to the forest conditions, we adopted an angle of $1.146^{\circ}(\mathrm{BAF}=1.0)$ 
for most plots. However, for some plots at the Sg. Manila site (an oil palm plantation), we adopted an angle of $1.812^{\circ}(\mathrm{BAF}=2.5)$. In this approach, it is necessary to define a tree number expansion factor that equals the BAF divided by the basal area of each counted tree, which represents the number of trees per hectare with a diameter at breast height (DBH) equal to that of the counted tree. For example, if a tree with a DBH of $0.3 \mathrm{~m}$ is counted using $\mathrm{BAF}=1.0$, we can estimate that there are $1.0 /\left(0.15^{2} \pi\right)=14.15$ trees per hectare with a DBH of $0.3 \mathrm{~m}$. We measured the tree height and DBH of each counted tree to calculate the tree number expansion factor and used that factor to calculate AGB using an allometric model (described later in this section). We did not measure tree heights at the Palangka Raya site because the allometric model that we used for peat swamp forest only requires DBH data, as described later in this section. We used a Vertex IV ultrasonic hypsometer (Haglöf Sweden AB, Långsele, Sweden) for tree height measurements. The Bitterlich sampling technique enabled us to estimate the total basal area per hectare, and we could determine the AGB per hectare by multiplying the AGB of each counted tree by the tree number expansion factor. The AGB of each counted tree was calculated using suitable allometric models, which are described in the following paragraphs.

In the peat swamp forest sites (Palangka Raya), we calculated AGB from the DBH of each counted tree using two allometric models developed by Miyamoto et al. [39]:

$$
\begin{aligned}
& \ln (1 / H)=\ln \{(1 / 2.54 D)+(1 / 25.5)\} \\
& \ln W_{\mathrm{t}}=-4.321+1.084 \cdot\left(D^{2} H\right)
\end{aligned}
$$

where $H$ is the tree height $(\mathrm{m}), D$ is the $\mathrm{DBH}(\mathrm{cm})$, and $W_{\mathrm{t}}$ is stem biomass $\left(\mathrm{Mg} \mathrm{ha}^{-1}\right)$. These equations were developed using measurements of felled trees in the Setia Alam peat swamp forest, $20 \mathrm{~km}$ southwest of Palangka Raya City. We calculated the stem biomass of each counted 
tree using Eqs. (1) and (2). We then calculated the AGB, including branches and leaves, by multiplying the stem biomass by a biomass expansion factor (a different factor from the tree number expansion factor described above), which was 1.29 for the peat swamp forest around the study area [39].

At the secondary forest (Kg. Ulu Kimanis and Tenom) and the forest reserve (Ulu Tungud) sites, we compared five types of allometric models that have been widely used for tropical forest: the models of Brown [40], Chave et al. [41] (two models), Yamakura et al. [42], and Kenzo et al. [43]. The two models of Chave et al. used only DBH or used both DBH and tree height.

$$
\text { Brown: } \quad A G B=\exp (-2.134+2.53 \cdot \ln D)
$$

Chave (D): $A G B=\rho \cdot \exp \left\{-1.499+2.148 \cdot \ln D+0.207 \cdot(\ln D)^{2}-0.0281(\ln D)^{3}\right\}$

$$
\begin{aligned}
& \text { Chave }(\mathrm{D} \text { and } \mathrm{H}): \quad A G B=\exp \left\{-2.977+\ln \left(\rho D^{2} H\right)\right\} \\
& \text { Yamakura: } W_{\mathrm{s}}=0.02903 \cdot\left(D^{2} H\right)^{0.9813} \\
& \qquad \begin{array}{l}
W_{\mathrm{b}}=0.1192 \cdot W_{\mathrm{s}}^{1.059} \\
W_{\mathrm{l}}=0.09146 \cdot\left(W_{\mathrm{s}}+W_{\mathrm{b}}\right)^{0.7266} \\
A G B=W_{\mathrm{s}}+W_{\mathrm{b}}+W_{\mathrm{l}} \\
\text { Kenzo: } \quad A G B=0.0829 \cdot D^{2.43}
\end{array}
\end{aligned}
$$

where $A G B$ is the aboveground biomass $(\mathrm{kg}), D$ is the $\mathrm{DBH}(\mathrm{cm}), \rho$ is the species-specific wood density $\left(\mathrm{g} \mathrm{cm}^{-3}\right), H$ is the tree height $(\mathrm{m}), W_{\mathrm{s}}$ is the stem biomass $(\mathrm{kg}), W_{\mathrm{b}}$ is the branch biomass $(\mathrm{kg})$, and $W_{1}$ is the leaf biomass $(\mathrm{kg})$. We used the GPG-LULUCF data [44] for the values of wood density; we adopted a value of $\rho=0.53$ (for Macaranga denticulata) for the secondary forest sites (Kg. Ulu Kimanis and Tenom) and a value of $\rho=0.61$ (for Dipterocarpus spp.) for 
the forest reserve site (Ulu Tungud). Brown's model has been used in many previous studies, and it was developed using the data collected by several authors from different tropical countries. Chave's models are improved versions of Brown's model. Yamakura's model was developed for the Indonesian part of Borneo. Kenzo's model was developed for lowland dipterocarp forests in Sarawak, Borneo.

Figure 3 compares the AGB estimates from the five allometric models using the field-measured data from this study. The models of Brown and Chave (D) provided similar results, and the models of Chave (D and $\mathrm{H}$ ) and Yamakura also provided similar results. These similarities can be explained by the fact that the first two models use only $\mathrm{DBH}$, and the second two use both DBH and tree height. The models based only on DBH predicted higher AGB at most plots. Kenzo's model provided lower AGB than the other four models in most plots. Chave et al. [41] reported that their model which accounted for tree height (Eq. 5) estimated AGB more accurately than their model without tree height (Eq. 4). On that basis, we adopted the average AGB of the values calculated from the models of Chave (D and H) and Yamakura, which both account for tree height.

At the oil palm plantation site (Sg. Manila), we calculated AGB using an allometric model developed by Khalid et al. [45]:

$$
W_{\mathrm{o}}=725+197 \cdot H
$$

where $W_{\mathrm{o}}$ is the total fresh weight $(\mathrm{kg})$ and $H$ is the tree height $(\mathrm{m})$. We applied a dry weight to fresh weight ratio of 0.27 to convert the fresh weight into AGB [45].

Finally, we calculated the total AGB per hectare by multiplying the expansion factor by the AGB of each counted tree, and summing the results for all of the counted trees. The AGB 
calculated in this way for each of the 37 plots was used as the ground-referenced AGB in our model development. Here, even the ground-referenced values might contain some errors; the main error sources were errors in the Bitterlich sampling and in the allometric model. Previous studies found that the error in Bitterlich sampling is not significantly different from the error that results from measuring every tree [e.g., 46]. In contrast, Chave et al. reported that the error in an allometric model that used both DBH and canopy height was 12.5\% [41]. An additional error may have resulted from the time lag between the field measurements and the GLAS observations, but we did not correct for this error, because any large-scale disturbance of the forest was easily visible, and data from such sites could be excluded from the dataset used in our analysis.

\subsection{Model development}

We developed an AGB estimation model from the GLAS data using the ground-referenced data acquired through the field measurements described above. The GLAS data for the field-measured sites were acquired from 2004 to 2009, of which 23 plots (62\%) were in 2007. There was therefore a time lag of 6 to 7 years between the GLAS observations and our field measurements (2013 to 2014), and changes in forest biomass during this period might have contributed to the estimation error in the GLAS-based AGB modeling. The reason is because differences between the AGB values at the ground reference and the GLAS observation might make the estimation model inappropriate. However, we could identify heavy disturbed forests in the field measurements because evidence of the disturbance remained visible even 7 years later, and we were able to exclude such sites from the target for the field measurements.

We conducted multiple-regression analysis to estimate AGB directly from 14 parameters of 
the GLAS waveform (Table 1). In this analysis, we selected the best of these parameters (i.e., the ones that produced the best fit to the ground-referenced data) using multiple regression.

The parameter selection method was intended to prevent a problem with multicollinearity, which occurs when some parameters are strongly correlated. Ideally, the analysis should select parameters for which the variance inflation factors (VIF) are smaller than 5.0 to avoid multicollinearity [e.g., 47]. We conducted multiple-regression analysis using every combination of the 14 parameters, and selected the combination of parameters with the highest adjusted $R^{2}$ but that also had VIF $<5.0$ for each parameter. This approach seeks a compromise between two problems: a large number of parameters may lead unacceptable multicollinearity, but a small number of parameters may decrease the adjusted $R^{2}$. Therefore, the number of parameters chosen in this approach is typically an intermediate value. In addition, we also investigated whether the estimation accuracy could be improved by developing separate models for gentle and steep slopes, because the characteristics of the GLAS waveform change according to the ground's slope. We divided the gentle and steep slopes at a threshold terrain index (TI, the range of ground elevations within a fixed area; see Table 1) of $15 \mathrm{~m}$. On this basis, $45.9 \%$ of the signals were obtained from sites with a steep slope. We adopted the leave-one-out cross-validation procedure to verify the estimation accuracy, and used the root-mean-square error (RMSE) to represent the accuracy.

We also developed a canopy height estimation model using the GLAS waveform. Although the main objective of this study was to estimate AGB from spaceborne LiDAR data, we used a canopy height threshold to exclude GLAS data from non-forested areas (see section 2.5 for details), because some GLAS data were located in non-forested areas despite the data screening 
procedure described in Section 2.2. Several previous studies have developed methods to estimate canopy height from GLAS data, and we adopted a method based on three parameters: the waveform extent, the lead10 (L10), and the trail10 (T10) [34]. Because we did not measure tree height at the Palangka Raya site, we used data from the other 26 plots to develop an estimation model by means of multiple regression. Here, we used Lorey's height to represent the canopy height. Lorey's height is a basal-area-weighted height, and it therefore primarily reflects the canopy heights of the upper story trees. We verified the estimation accuracy by means of leave-one-out cross-validation, as in the AGB estimation model. Although, some previous studies used RH1OO (the height difference between the ground peak and the start of the signal) to represent canopy height [e.g., 48], this parameter cannot be used on steep slopes because $R H 100$ is greatly affected by the pulse-broadening effect that occurs on such slopes. A comparison between $R H 100$ and the canopy height in the ground-referenced data from the present study revealed that $R H 100$ was larger than the canopy heights in all plots, and the mean difference was $+11.1 \mathrm{~m}$. Therefore, it's necessary to correct for pulse broadening in estimates of canopy height by using parameters such as lead10 and trail10.

\subsection{Forest biomass estimation}

We assessed the forest resources in Borneo by applying the estimation model developed in section 2.4 to the GLAS data. The assessment was conducted to determine the (1) histogram of AGB, (2) temporal changes of AGB, (3) total AGB in Borneo, and (4) the spatial distribution of AGB.

First, we predicted AGB in each of the 127,862 GLAS footprints in Borneo (Figure 1). We 
then created an AGB histogram to clarify the forest resources characteristics throughout Borneo. The GLAS data that we used was extracted primarily from forested areas using land cover data from the GLC2000 map, but some data from non-forested areas remained. Therefore, we excluded GLAS data that had a canopy height smaller than a threshold. Many criteria have been proposed for determining the threshold canopy height. FAO's Global Forest Resources Assessments (FRA) adopted a threshold of 5 m [49], and the United Nations Framework Convention on Climate Change (UNFCCC) adopted country-specific thresholds of 2 to $5 \mathrm{~m}$ [44]. We adopted a threshold of $2 \mathrm{~m}$, because this was the lowest value in these estimates; as a result, we excluded any GLAS data for which canopy height was smaller than $2 \mathrm{~m}$.

We divided the GLAS data into two groups according to its observation period to assess temporal changes. For the initial period, we used GLAS data acquired between February 2003 and March 2005; for the second period, we used GLAS data acquired between May 2005 and April 2009. These periods were chosen because they divided the GLAS data into almost equal numbers of observations for the two periods. The mean observation date (year) for the first set of GLAS data was $2004.45 \pm 0.64$ (mean \pm one standard deviation), versus $2007.02 \pm 1.12$ for the second set. Therefore, we could assess the change over a period of almost 3 years. We created separate AGB histograms for each dataset, and figured out the AGB change over 3 years. Two factors potentially contaminated the GLAS data despite the screening using the GLC2000 map: (1) errors in the GLC2000 map caused by mis-classifying non-forested area as forested area, and (2) forested area that was lost as a result of logging, fires and so on or generated by reforestation and natural regrowth. The equations that describe these factors are as follows:

$$
N_{2004}=E_{2004}+D_{2000-2004}
$$




$$
N_{2007}=E_{2007}+D_{2000-2007}
$$

where $N_{2004}$ and $N_{2007}$ are the proportions (\%) of non-forested GLAS data (canopy height $<2 \mathrm{~m}$ ) in the two GLAS datasets, $E_{2004}$ and $E_{2007}$ are the proportions (\%) of error type (1), and $D_{2000-2004}$ and $D_{2000-2007}$ are the proportions (\%) of error type (2). We assumed that error type (1) occurred at a constant rate, regardless of the location (i.e., $E_{2004}=E_{2007}$ ). On that basis, the temporal change can be described as follows:

$$
N_{2007}-N_{2004}=D_{2000-2007}-D_{2000-2004}=D_{2004-2007}
$$

where $D_{2004-2007}$ is the rate of forest net loss (\%) during the 3-year period, which represents the interval between the mean dates in the two GLAS datasets. We estimated the rate of forest loss in this way, and compared it with the results from previous studies.

We also estimated the total AGB in Borneo. To do so, we overlaid the GLAS data on the GLC2000 map and GIS data for the provincial boundaries, then calculated the average GLAS-estimated AGB for each forest type and each province. We multiplied these values by the area of each category (forest type and province), and summed them up to estimate the total AGB in Borneo. We compared this with the results from previous studies. Here, the total AGB represented the average of the values in 2003 and 2009, when the GLAS data was acquired.

Finally, we calculated the average AGB for each $20-\mathrm{km}$ grid cell throughout Borneo to clarify the spatial distribution of AGB, because GLAS observed only discrete points. We directly adopted the average value for each grid cell that contained five or more GLAS footprints, and then used kriging interpolation to determine the AGB for grid cells that contained fewer than five footprints. 


\section{Results}

\subsection{Model development}

We developed the GLAS-based AGB estimation model by multiple-regression analysis using field-measured ground-referenced data from 37 forest plots. We examined all the combinations of GLAS waveform parameters in the multiple-regression analysis, and selected the most suitable combination (the one with the highest adjusted $R^{2}$ and with VIF $<5.0$ for each parameter). We obtained the following best-fit "unified" model that included all data and did not account for slope:

$$
A G B_{\mathrm{U}}=5.89 \cdot W E+31.4 \cdot R H 10-6.92 \cdot R H 60-1.35 \cdot T I-31.1
$$

where $A G B_{\mathrm{U}}$ is the unified (i.e., all slopes combined) $\mathrm{AGB}\left(\mathrm{Mg} \mathrm{ha}^{-1}\right), W E$ is the waveform extent (m), RHIO and $R H 60$ are the relative heights at $10 \%$ and $60 \%$ of the energy return (m), and $T I$ is the terrain index (m). WE showed the highest correlation with AGB. Based on the cross-validation, the RMSE of the model was $39.8 \mathrm{Mg} \mathrm{ha}^{-1}$. We also obtained separate estimation models for gentle and steep slopes:

Gentle slope:

$$
A G B_{\mathrm{G}}=2.41 \cdot W E+19.0 \cdot R H 10+1.17 \cdot(L E+T E)-5.22 \cdot T I+28.1
$$

Steep slope:

$$
A G B_{\mathrm{S}}=8.64 \cdot W E+52.5 \cdot R H 10-18.3 \cdot R H 60-2.22 \cdot T I+6.77
$$

where $A G B_{\mathrm{G}}$ is the $\mathrm{AGB}\left(\mathrm{Mg} \mathrm{ha}^{-1}\right)$ for gentle slopes $(T I \leq 15 \mathrm{~m}), A G B_{\mathrm{S}}$ is the $\mathrm{AGB}\left(\mathrm{Mg} \mathrm{ha}^{-1}\right)$ for steep slopes $(T I>15 \mathrm{~m})$, and $L E$ and $T E$ are the leading and trailing edges of the waveform (m). The steep slope model (Eq. 17) used the same parameters as the unified model (Eq. 15), but the gentle slope model (Eq. 16) used slightly different parameters (i.e., it included LE and TE). 
Based on the cross-validation, the RMSEs were $27.8 \mathrm{Mg} \mathrm{ha}^{-1}$ for the gentle slope model, 49.0 $\mathrm{Mg} \mathrm{ha}^{-1}$ for the steep slope model, and $38.7 \mathrm{Mg} \mathrm{ha}^{-1}$ for the combination of the two models; we refer to this as the slope-based estimate. The slope-based estimate, which used separate models for gentle and steep slopes (Eqs. 16 and 17), had a lower RMSE than the unified model (Eq. 15); we therefore adopted the slope-based estimates in our subsequent analyses. Figure 5a compares the ground-referenced AGB with the GLAS-estimated AGB using models 16 and 17. We found a strong and statistically significant relationship between the two sets of values $\left(R^{2}=0.883, p<\right.$ 0.001).

We also developed a GLAS-based estimation model for canopy height by means of multiple-regression analysis using the field-measured ground-referenced data from 26 plots, excluding the Palangka Raya site. We obtained the following model:

$$
H=0.658 \cdot W E-0.445 \cdot(L 10+T 10)-2.98
$$

where $H$ is the canopy height (Lorey's height; $\mathrm{m}), L 10$ is the lead10 parameter (m), and T10 is the trail10 parameter $(\mathrm{m})$. Based on the leave-one-out cross-validation, the RMSE of this model was $4.0 \mathrm{~m}$. We also developed separate estimation models for heights on gentle and steep slopes, as in the AGB analysis, but the RMSE did not improve, so we did not adopt separate models to replace the unified height model for all slopes combined. Figure $5 b$ compares the ground-referenced canopy height with the GLAS-estimated canopy height. We found a strong and statistically significant relationship between the two sets of values $\left(R^{2}=0.757, p<0.001\right)$.

\subsection{Forest biomass estimation}

We assessed the quantity and distribution of Borneo's forest resources by applying the 
slope-based estimation model to the GLAS data to describe the (1) histogram of AGB, (2) temporal change of AGB, (3) total AGB in Borneo, and (4) spatial distribution of AGB.

First, we applied the estimation models for steep and gentle slopes (Eqs. 16 and 17) to the 127,862 points GLAS data points in Borneo, and created the AGB histogram (Figure 6a). The red bars in the histogram represent the non-forested GLAS data, whose canopy height was $<2$ $\mathrm{m}$; these accounted for $14.7 \%(18,828$ points $)$ of the total data points. After these data were excluded, the average AGB in Borneo was $191.8 \pm 130.9 \mathrm{Mg} \mathrm{ha}^{-1}$ (mean \pm one standard deviation).

Next, we estimated the temporal change in AGB by comparing the two GLAS datasets with a mean interval of 2.57 years (Figure 6b). The above-mentioned non-forested GLAS data (estimated canopy height $<2 \mathrm{~m}$ ) was excluded from the histograms. The sample sizes were similar in the two GLAS datasets: 54,420 points for the 2003-2005 dataset, and 54,614 points for the 2005-2009 dataset. Comparing the two estimates shows that AGB decreased by $\mathbf{3 3 . 1} \mathrm{Mg} \mathrm{ha}^{-1}$, from $208.3 \pm 136.3 \mathrm{Mg} \mathrm{ha}^{-1}$ (mean \pm one standard deviation) to $175.2 \pm 123.1 \mathrm{Mg} \mathrm{ha}^{-1}$, during the study period based on these histograms. The standard error (SE) and 95\% confidence interval $(C I)$ for each dataset were $S E_{2003-2005}=0.584 \mathrm{Mg} \mathrm{ha}^{-1}, S E_{2005-2009}=0.526 \mathrm{Mg} \mathrm{ha}^{-1}, C I_{2003-2005}=$ 1.14 $\mathrm{Mg} \mathrm{ha}^{-1}$, and $C I_{2005-2009}=1.03 \mathrm{Mg} \mathrm{ha}^{-1}$, and the decrease in AGB was statistically significant as a result of $t$-test. We estimated the rate of net forest loss in Borneo by applying Eq. 14 to the GLAS data. We found that $6.2 \%$ of the forested area was lost during the 2.57 years between 2004 and 2007, for a mean loss rate of $2.4 \%$ per year. The rates of forest loss in the Malaysian and Indonesian parts of Borneo during the same period were $3.5 \%$ and $7.4 \%$, respectively, for mean annual rates of $1.4 \%$ and $2.9 \%$, respectively. These results mean that the 
Indonesian forests were lost at twice the rate of the Malaysian forests. Table 3 compares these values with the results of previous studies. The results in this study are generally higher than those in previous studies.

We also estimated the total AGB in Borneo. As a result of integrating the average GLAS-estimated AGB for each province and each forest type, AGB in Borneo totaled 10.34 Gt. This result is lower than previous estimates (Table 4). We calculated the $95 \%$ confidence interval for $\mathrm{AGB}$ in each category (province and forest type), and integrated them; the resulting confidence intervals for total AGB in Borneo was 0.17 Gt. However, confidence intervals were not reported in the previous studies shown in Table 4. Therefore, we cannot state whether the differences between these studies and the present study were statistically significant.

Finally, we overlaid a grid of $20-\mathrm{km}$ cells on Borneo, and calculated the average GLAS-estimated AGB for each cell to clarify the spatial distribution of AGB. We found 1,151 grid cells that contained at least five GLAS footprints, which accounted for $56.8 \%$ of the total number of cells (2,025 cells). We used kriging interpolation to calculate AGB for cells in the grid that contained fewer than five footprints. Figure 7 shows the results of this analysis (i.e., the distribution of AGB throughout Borneo). Areas with high biomass were distributed mainly in the mountainous regions, and areas with low biomass were distributed mainly in lowland regions.

\section{Discussion}

Duncanson et al. pointed out that GLAS waveforms are more complex in areas with dense forests, high relief, or heterogeneous vegetation cover [52]. These three factors may be the main factors that affect the estimation accuracy of canopy height and AGB. To reduce the influence of 
high relief, we separated the AGB estimation into models for gentle and steep slopes. If map data were available for stand density and vegetation heterogenecity in the forested area of Borneo, it would be possible to develop estimation models to account for these factors, and this would increase the AGB accuracy. Unfortunately, such data are currently unavailable. The Japan Aerospace Exploration Agency (JAXA) plans to send a LiDAR system named the Multi-footprint Observation Lidar and Imager (MOLI) to the International Space Station [53]. MOLI will carry a color camera with 2-m spatial resolution, and the image data will provide information about stand density and vegetation heterogenecity.

The rate of forest loss estimated from the GLAS data was higher than in most previous studies (Table 3), although it was not clear whether the differences were statistically significant. One possible explanation is that the loss rate in the GLAS observation period (2004-2007) was higher than that in the other periods. Bontemps et al. estimated the forest loss rate in Borneo using SPOT/Vegetation time-series data for every year between 2000 and 2008 [51]. They found forest loss rates of between 1.3 and 2.7\%, and the maximum rate occurred from 2005 to 2006 . Broich et al. estimated the loss of forested area using Landsat/TM and MODIS data for every year between 2000 and 2008 [54]. Their study area was Sumatra and Kalimantan, the Indonesian part of Borneo, in which the maximum forest loss was observed from 2005 to 2007. Accordingly, the forest loss rate around 2006 was higher than that during other periods, and this may explain why the rate in the present study was higher than in most other studies.

Why were forests lost at such a high rate around 2006? The cause appears to be an increased fire frequency caused by droughts related to El Niño, which occurred in 2006. Langner and Siegert monitored fires in Borneo using satellite data between 1997 and 2006, and found that the 
fire frequency was much higher throughout Borneo in El Niño years (1997-1998, 2002, and 2006) than in other years [55]. Moreover, they found that the fire-affected area in the Indonesian part of Borneo averaged five times that in the Malaysian part and in Brunei Darussalam. This tendency was consistent with our results, which showed that the forest loss rate in the Indonesian part $\left(2.9 \% \mathrm{yr}^{-1}\right)$ was two times that in the Malaysian part $\left(1.4 \% \mathrm{yr}^{-1}\right)$. Van der Werf et al. analyzed MODIS data between 2000 and 2008, and also found that the forest loss rate was linked with fires associated with El Niño, and that an especially large forested area was lost during the 2006 El Niño [56]. Forest loss monitoring has usually depended on satellite optical imagery in the past. However, the present study showed that spaceborne LiDAR can also be used to monitor the rate of forest loss, and will have potentially important future applications.

We compared the total AGB in Borneo with results from previous studies (Table 4). Miettinen and Liew estimated forest biomass in Southeast Asia using land cover maps based on MODIS data, and assigned typical AGB values to each land cover type before summing these values [57]. Both Saatchi et al. and Baccini et al. developed pantropical forest biomass maps using a combination of MODIS and GLAS data $[17,22]$. These studies differed in their methods of analysis, field data, and other factors, and Baccini et al. seemed to slightly underestimate values in southeast Asia [58]. To provide values for Borneo, we summed their data (Sattchi et al. [17] and Baccini et al. [22]) only for the parts of their map in Borneo, and multiplied these values by the forest cover ratio (71.7\%) estimated using the GLC2000 map. The previous studies all estimated a larger AGB than in this study. There are some possible reasons for these differences, including differences in the setting of canopy height threshold, in the acquisition period of the satellite data, and in the distribution of ground-referenced data. However, it is not 
clear which of the estimates is closest to the true value. Therefore, additional research should be conducted to find ways to more accurately estimate AGB.

As we noted in the Introduction, spaceborne LiDAR data may play an important role in the implementation of REDD+ schemes. REDD+ requires the ability to measure forest carbon stocks and changes in forest cover for each forest type, which are used to estimate $\mathrm{CO}_{2}$ emissions from deforestation and forest degradation. The measurements of forest carbon stocks can be classified into three levels of complexity: Tier 1 uses IPCC default values, Tier 2 uses country-specific values, and Tier 3 requires highly disaggregated data such as that contained in a national forest inventory. The higher tiers are more specific to the target forests and provide higher accuracy, and should therefore be used wherever possible [3]. Based on the Tier 1 default values for the Asian insular region, for example, the AGB of tropical rain forest averages $348 \mathrm{Mg} \mathrm{ha}^{-1}$ (range: 280 to 520) [44]. These values are clearly larger than the average AGB for Borneo estimated in this study (191.8 $\left.\mathrm{Mg} \mathrm{ha}^{-1}\right)$. Therefore, using the Tier 1 values may lead to a large error in estimating $\mathrm{CO}_{2}$ emissions. In contrast, spaceborne LiDAR is expected to be capable of providing Tier 2 or 3 values, which will permit more accurate monitoring using suitable values for each region. Furthermore, the synergistic use of spaceborne LiDAR combined with satellite imagery should enable us to create an AGB map that thoroughly covers a target area and to estimate $\mathrm{CO}_{2}$ emissions directly. Thus, spaceborne LiDAR has great potential to provide accurate monitoring to support REDD+ schemes.

\section{Conclusions}

We examined the potential of using spaceborne LiDAR to estimate Borneo's forest biomass, 
in the context of finding a way to support REDD+ implementations. We obtained the following main results:

- Based on field-measured data in Borneo, we developed models to estimate AGB and canopy height (Lorey's height) from GLAS waveform data. Based on cross-validation, the RMSEs of the AGB and canopy height models were $38.7 \mathrm{Mg} \mathrm{ha}^{-1}$ and $4.0 \mathrm{~m}$, respectively.

- The forest AGB in Borneo was estimated to be $191.8 \pm 130.9 \mathrm{Mg} \mathrm{ha}^{-1}$ (mean \pm one standard deviation), and totaled $10.34 \mathrm{Gt}$.

- GLAS data acquired from 2003 to 2005 (an average date (year) of 2004.45) gave an average AGB of $208.3 \pm 136.3 \mathrm{Mg} \mathrm{ha}^{-1}$ (mean \pm one standard deviation), whereas GLAS data acquired from 2005 to 2009 (an average date of 2007.02) gave 175.2 $\pm 123.1 \mathrm{Mg} \mathrm{ha}^{-1}$. Thus, AGB decreased by $33.1 \mathrm{Mg} \mathrm{ha}^{-1}$ during this period of 2.57 years. We also estimated the GLAS-based canopy height to identify non-forested data points contained in the GLAS data, and found that the rate of net forest loss in Borneo was $2.4 \%$ year $^{-1}$ from 2004 to 2007 . The rate of forest loss in the Indonesian part of Borneo (2.9\%) was twice that in the Malaysian $\operatorname{part}(1.4 \%)$.

- We determined the spatial distribution of AGB for each cell in a $20-\mathrm{km}$ grid covering the island.

The results show that spaceborne LiDAR permitted efficient and reasonably accurate large-scale estimation of AGB and canopy height. Thus, this approach can be used for estimating total AGB, its temporal change, and the net loss for the whole Bornean forest. In the near future, 
we will need such tools to assess forest resources over large areas, especially in a context of REDD+ implementation. Therefore, spaceborne LiDAR will prove to be increasingly important.

\section{Future perspective}

The development of time-series maps of forest biomass will provide important support for implementation of REDD+ schemes. To provide this support, many researchers are trying to find ways to develop accurate forest biomass maps from satellite imagery, some using biomass data estimated from spaceborne LiDAR as training data [17, 22].

Since ICESat ceased operation, there has been no spaceborne lidar system capable of observing land surfaces. However, ICESat-2 is scheduled to be launched in 2017, and it will include an improved LiDAR system. Moreover, there are plans to mount spaceborne LiDAR systems for forest observation on the International Space Station: the Global Ecosystem Dynamics Investigation (GEDI; United States), and the Multi-footprint Observation Lidar and Imager (MOLI; Japan). These next-generation spaceborne LiDAR systems will play an important role in forest resource monitoring in the future.

\section{Executive summary}

Background:

- There is increasing demand for technology for monitoring forest resources efficiently and accurately on a large scale.

- Spaceborne light detection and ranging (LiDAR) is expected to provide accurate estimates to meet this demand. 
- We aimed to clarify the potential of spaceborne LiDAR to estimate forest biomass resources on a large scale.

- Borneo was adopted for the study area, as it is experiencing one of the most rapid rates of forest cover loss in the world.

- We used ICESat/GLAS data to estimate forest aboveground biomass (AGB), its temporal change, and the rate of forest loss in Borneo.

Results:

- We developed empirical models to estimate AGB and canopy height from GLAS data, with the best models chosen using field-measured data. The root-mean-square errors were $38.7 \mathrm{Mg} \mathrm{ha}^{-1}$ for AGB and $4.0 \mathrm{~m}$ for canopy height.

- We applied the model to the GLAS data for all of Borneo, and found an average AGB of 191.8 $\mathrm{Mg} \mathrm{ha}^{-1}$.

- To assess the temporal changes, we divided the GLAS data into two periods (data acquired around 2004 and around 2007), and found an average AGB decrease of $33.1 \mathrm{Mg} \mathrm{ha}^{-1}$.

- We estimated the rate of forest loss based on the GLAS-based canopy height; it equaled $\mathbf{2 . 4 \%}$ year ${ }^{-1}$ between 2004 and 2007.

- The total AGB in Borneo was 10.34 Gt.

Conclusion:

- The spaceborne LiDAR was capable of estimating AGB and rates of forest loss over large areas with acceptable accuracy.

- Spaceborne LiDAR will play an important role in supporting the future demand for monitoring forest resources under programs such as REDD+. 


\section{References}

Papers of special note have been highlighted as:

* of interest

** of considerable interest

1. Gibbs HK, Brown S, Niles JO et al. Monitoring and estimating tropical forest carbon stocks: making REDD a reality. Environ. Res. Lett. 2(4), 045023 (2007).

2. de Sy V, Herold M, Achard F et al. Synergies of multiple remote sensing data sources for REDD+ monitoring. Curr. Opin. Environ. Sustain. 4, 1-11 (2012).

3. GOFC-GOLD. A sourcebook of methods and procedures for monitoring and reporting anthropogenic greenhouse gas emissions and removals associated with deforestation, gain and losses of carbon stocks in forests remaining forests, and forestation: GOFC-GOLD Report version COP19-2. GOFC-GOLD Land Cover Project Office, Wageningen University, The Netherlands (2013).

4. Intergovernmental Panel on Climate Change (IPCC). IPCC Guidelines for National Greenhouse Gas Inventories. ed. by Intergovernmental Panel on Climate Change. Hayama, Japan (2006).

5. Gleason CJ, Im J. A review of remote sensing of forest biomass and biofuel: options for small-area applications. GIScience \& Rem. Sens. 48(2), 141-170 (2011).

6. Goetz SJ, Baccini A, Laporte N T et al. Mapping and monitoring carbon stocks with satellite observations: a comparison of methods. Carbon Bal. Manag. 4(2), (2009).

7. Song C. Optical remote sensing of forest leaf area index and biomass. Progr. Phys. Geogr. 
37(1), 98-113 (2012).

8. Patenaude G, Milne R, Dawson T P. Synthesis of remote sensing approaches for forest carbon estimation: reporting to the Kyoto Protocol. Environ. Sci. Pol. 8(2), 161-178 (2005).

9. Shugart HH, Saatchi S, Hall FG. Importance of structure and its measurement in quantifying function of forest ecosystems. J. Geophys. Res. 115, G00E13 (2010).

10. Hall FG, Bergen K, Blair JB et al. Characterizing 3D vegetation structure from space: mission requirements. Rem. Sens. Environ. 115(11), 2753-2775 (2011).

* Detailed arguments about the potential of spaceborne LiDAR for forest observation.

11. Koch B. Status and future of laser scanning, synthetic aperture radar and hyperspectral remote sensing data for forest biomass assessment. ISPRS J. Photogramm. Remote Sens. 65(6), 581-590 (2010).

12. Abshire JB, Sun X, Riris H et al. Geoscience Laser Altimeter System (GLAS) on the ICESat mission: on-orbit measurement performance. Geophys. Res. Lett. 32, L21S02 (2005).

13. Schutz BE, Zwally HJ, Shuman CA et al. Overview of the ICESat Mission. Geophys. Res. Lett. 32, L21S01 (2005).

14. Wang X, Cheng X, Gong P. Earth science applications of ICESat/GLAS: a review. Int. J. Rem. Sens. 32(23), 8837-8864 (2011).

15. Lefsky MA, Harding DJ, Keller M et al. Estimates of forest canopy height and aboveground biomass using ICESat. Geophys. Res. Lett. 32, L22S02 (2005).

* Remarkable study during the early stages of ICESat/GLAS application for forest observations. 
16. Popescu SC, Zhao K, Neuenschwander A, Lin C. Satellite lidar vs. small footprint airborne lidar: Comparing the accuracy of aboveground biomass estimates and forest structure metrics at footprint level. Rem. Sens. Environ. 115(11), 2786-2797 (2011).

17. Saatchi SS, Harris NL, Brown S et al. Benchmark map of forest carbon stocks in tropical regions across three continents. Proc. Natl. Acad. Sci. Unit. States Am. 108(24), 9899-9904 (2011).

* First study to apply ICESat/GLAS data to developing a pan-tropical forest biomass map.

18. Boudreau J, Nelson R, Margolis H et al. Regional aboveground forest biomass using airborne and spaceborne LiDAR in Québec. Rem. Sens. Environ. 112(10), 3876-3890 (2008).

19. Nelson R, Boudreau J, Gregoire TG et al. Estimating Quebec provincial forest resources using ICESat/GLAS. Can. J. Forest Res. 39(4), 862-881 (2009).

20. Guo Z, Chi H, Sun G. Estimating forest aboveground biomass using HJ-1 Satellite CCD and ICESat GLAS waveform data. Sci. China Earth Sci. 53(S1), 16-25 (2010).

21. Nelson R, Ranson KJ, Sun G et al. Estimating Siberian timber volume using MODIS and ICESat/GLAS. Rem. Sens. Environ. 113(3), 691-701 (2009).

22. Baccini A, Goetz S, Walker W et al. Estimated carbon dioxide emissions from tropical deforestation improved by carbon-density maps. Nat. Clim. Change 2, 182-185 (2012).

23. Broich M, Hansen M, Stolle F et al. Remotely sensed forest cover loss shows high spatial and temporal variation across Sumatera and Kalimantan, Indonesia 2000-2008. Environ. Res. Lett., 6(1), 014010 (2011). 
24. Hansen MC, Potapov PV, Moore R et al. High-resolution global maps of 21st-century forest cover change. Science 342(6160), 850-853 (2013).

25. Ballhorn U, Jubanski J, Siegert F. ICESat/GLAS Data as a Measurement Tool for Peatland Topography and Peat Swamp Forest Biomass in Kalimantan, Indonesia. Rem. Sens. 3(9), 1957-1982 (2011).

26. Miettinen J, Shi C, Liew SC. Deforestation rates in insular Southeast Asia between 2000 and 2010. Global Change Biol. 17(7), 2261-2270 (2011).

27. Gaveau DLA, Sloan S, Molidena E et al. Four Decades of Forest Persistence, Clearance and Logging on Borneo. PLoS ONE 9(7), e101654 (2014).

28. NSIDC. Attributes for ICESat Laser Operations Periods. (2012). http://nsidc.org/data/icesat/laser_op_periods.html (accessed on 31 October 2014).

29. Hayashi M, Saigusa N, Oguma H, Yamagata Y. Forest canopy height estimation using ICESat/GLAS data and error factor analysis in Hokkaido, Japan. ISPRS J. Photogramm. Remote Sens. 81, 12-18 (2013).

30. Miller ME, Lefsky M, Pang Y. Optimization of Geoscience Laser Altimeter System waveform metrics to support vegetation measurements. Rem. Sens. Environ., 115(2), 298305 (2011).

31. Drake JB, Dubayah RO, Clark DB et al. Estimation of tropical forest structural characteristics using large-footprint lidar. Rem. Sens. Environ. 79(2-3), 305-319 (2002).

32. Chen Q. Retrieving vegetation height of forests and woodlands over mountainous areas in the Pacific Coast region using satellite laser altimetry. Rem. Sens. Environ. 114(7), 16101627 (2010). 
** Intensive study about canopy height estimation methodology using ICESat/GLAS

data.

33. Lefsky MA, Keller M, Pang Y et al. Revised method for forest canopy height estimation from Geoscience Laser Altimeter System waveforms. J. Appl. Remote Sens. 1(1), 013537 (2007).

34. Lefsky MA. A global forest canopy height map from the Moderate Resolution Imaging Spectroradiometer and the Geoscience Laser Altimeter System. Geophys. Res. Lett. 37, L15401 (2010).

35. Miettinen J, Liew SC. Status of peatland degradation and development in Sumatra and Kalimantan. Ambio 39(5-6), 394-401 (2010).

36. Page SE, Rieley JO, Banks CJ. Global and regional importance of the tropical peatland carbon pool. Global Change Biol. 17, 798-818 (2011).

37. Hooijer A, Page S, Canadell JG et al. Current and future $\mathrm{CO}_{2}$ emissions from drained peatlands in Southeast Asia. Biogeosciences 7, 1505-1514 (2010).

38. Suzuki R, Kim Y, Ishii R. Sensitivity of the backscatter intensity of ALOS/PALSAR to the above-ground biomass and other biophysical parameters of boreal forest in Alaska. Polar Sci. 7(2), 100-112 (2013).

39. Miyamoto K, Kohyama T, Rahajoe JS et al. Tree Allometry, forest structure and productivity of tropical heath and peat swamp forests. In: Carbon management and ecosystem functions of tropical peatland. Springer, Berlin, Germany (In press).

40. Brown S. Estimating biomass and biomass change of tropical forests: a primer. FAO. Forestry Paper 134. FAO, Rome (1997). 
* Widely used allometric models for tropical forests.

41. Chave J, Andalo C, Brown S et al. Tree allometry and improved estimation of carbon stocks and balance in tropical forests. Oecologia 145, 87-99 (2005).

42. Yamakura T, Hagihara A, Sukardjo S, Ogawa H. Aboveground biomass of tropical rain forest stands in Indonesian Borneo. Vegetatio 68, 71-82 (1986).

43. Kenzo T, Ichie T, Hattori D et al. Development of allometric relationships for accurate estimation of above- and below-ground biomass in tropical secondary forests in Sarawak, Malaysia. J. Trop. Ecol. 25, 371-386 (2009).

44. Intergovernmental Panel on Climate Change (IPCC). Good Practice Guidance for Land Use, Land-Use Change and Forestry (GPG-LULUCF). IPCC National Greenhouse Gas Inventories Programme. Hayama, Japan (2003).

45. Khalid H, Zin ZZ, Anderson JM. Quantification of oil palm biomass and nutrient value in a mature plantation. I: Above-ground biomass. J. Oil Palm Res. 11(1), 23-32 (1999).

46. Piqué M, Obon B, Condés S, Saura S. Comparison of relascope and fixed-radius plots for the estimation of forest stand variables in northeast Spain: an inventory simulation approach. Eur. J. Forest Res. 130(5), 851-859 (2011).

47. Richard AB. Regression analysis: a constructive critique. Sage Publications, Thousand Oaks (2004).

48. Simard M, Pinto N, Fisher JB, Baccini A. Mapping forest canopy height globally with spaceborne lidar. J. Geophys. Res. 116, G04021 (2011).

49. Food and Agriculture Organization (FAO). Global forest resources assessment 2010 main report, FAO forestry paper 163. FAO, Rome (2010). 
50. Langner A, Miettinen J, Siegert F. Land cover change 2002-2005 in Borneo and the role of fire derived from MODIS imagery. Global Change Biol. 13(11), 2329-2340 (2007).

51. Duncanson LI, Niemann KO, Wulder MA. Estimating forest canopy height and terrain relief from GLAS waveform metrics. Rem. Sens. Environ. 114(1), 138-154 (2010).

52. Murooka J, Kobayashi T, Imai T, Suzuki K, Sakaizawa D, Yamakawa S, Sato R, Sawada H, Asai K. Overview of Japan's spaceborne vegetation lidar mission. Proc. SPIE 8894, Lidar Technologies, Techniques, and Measurements for Atmospheric Remote Sensing IX, 88940B (2013).

53. Bontemps S, Langner A, Defourny P. Monitoring forest changes in Borneo on a yearly basis by an object-based change detection algorithm using SPOT-VEGETATION time series. Int. J. Rem. Sens. 33(15), 4673-4699 (2012).

54. Broich M, Hansen M, Stolle F et al. Remotely sensed forest cover loss shows high spatial and temporal variation across Sumatera and Kalimantan, Indonesia 2000-2008. Environ. Res. Lett. 6, 014010 (2011).

55. Langner A, Siegert F. Spatiotemporal fire occurrence in Borneo over a period of 10 years. Global Change Biol. 15(1), 48-62 (2009).

** Detailed relationships between El Niño and fire occurence in Borneo.

56. van der Werf GR, Dempewolf J, Trigg SN et al. Climate regulation of fire emissions and deforestation in equatorial Asia. Proc. Natl. Acad. Sci. Unit. States Am. 105(51), 2035020355 (2008).

57. Miettinen J, Liew SC. Estimation of biomass distribution in Peninsular Malaysia and in the islands of Sumatra, Java and Borneo based on multi-resolution remote sensing land cover 
analysis. Mitig. Adapt. Strateg. Glob. Change, 14(4), 357-373 (2009).

58. Mitchard ET, Saatchi SS, Baccini A et al. Uncertainty in the spatial distribution of tropical forest biomass: a comparison of pan-tropical maps. Carb. Bal. Manage. 8(10), 1-13 (2013). 


\section{Table and Figure Legends}

Table 1. Description of the 14 candidate parameters that were examined to develop the aboveground biomass estimation model using the GLAS data. Units of measurement for all parameters are meters.

Table 2. Description of field measurement sites in Borneo used for ground-referencing of the GLAS data, and statistical data for canopy heights and aboveground biomass (AGB) at these sites. Canopy height is Lore's height.

Table 3. Comparison of rates of forest loss in Borneo between this study and previous studies. Bontemps et al. [53] estimated the rate for every year from 2000 to 2008, and the maximum and minimum values are shown. We summed the portions of the maps of Hansen et al. [24] for Borneo to calculate the rate of forest loss.

Table 4. Comparison of total aboveground biomass (AGB) estimates in Borneo between this study and previous studies. We summed the maps of Saatchi et al. [17] and Baccini et al. [22] only for values in Borneo, and multiplied them by the forest cover ratio (71.7\%) estimated from the GLC2000 map.

Figure 1. Distribution of the GLAS footprints (127,862 points) used for estimating forest biomass in Borneo. The image background shows the topography estimated from the Shuttle Radar Topography Mission (SRTM) elevations.

Figure 2. Distribution of the field measurement sites in Borneo used for ground-referencing of the GLAS data. The Palangka Raya site is located in the Indonesian part of Borneo, and the 
other four sites are located in the Malaysian part.

Figure 3. Comparison of the aboveground biomass (AGB) values estimated using the five allometric models described in section 2.3 and the field measurement data obtained from the secondary forest and forest reserve sites (Table 1). The GLAS AGB values estimated using separate equations for gentle and steep slopes (Eqs. 16 and 17) are also shown. The X-axis shows the identification numbers of the field plots; U represents the Ulu Tungud plots, $\mathrm{K}$ represents the Kg. Ulu Kimanis plots, and T represents the Tenom plot.

Figure 4. Comparison of GLAS waveforms for typical plots at the field measurement sites. The larger the AGB and canopy height, the longer the waveform extent (WE) and the more complicated the waveform becomes. The ground peak is not clear at the forest reserve site (Ulu Tungud), possibly because the GLAS laser was intercepted by the dense canopy and did not reach the ground.

Figure 5. Comparison of the field-measured values with the GLAS-estimated values. The straight line shows the 1:1 line. (a) Aboveground biomass. (b) Canopy height (Lorey’s height).

Figure 6. Aboveground biomass (AGB) histograms estimated from the GLAS data in Borneo: (a) based on 2003-2009 GLAS data, with the red bars showing data for non-forested sites (GLAS-estimated canopy height $<2 \mathrm{~m}$ ), (b) based on dividing the GLAS data into data from two periods (2003 to 2005 and 2005 to 2009), and excluding the non-forested data.

Figure 7. Spatial distribution of aboveground biomass (AGB) in Borneo. Values for cells containing five or more GLAS footprints were used to directly estimate AGB for each 20-km grid cell; AGB values for cells with fewer than five footprints were obtained by means of kriging interpolation. 
Table 1.

\begin{tabular}{|c|c|}
\hline Parameter & Description \\
\hline WE & Waveform extent: the distance between the signal start and signal end. \\
\hline RH10, RH20, .., RH100 & $\begin{array}{l}\text { Relative heights: the height relative to the ground return from which a given } \\
\text { percentage of the total waveform energy has been returned ( } 10 \% \text { for RH10, } 20 \% \text { for } \\
\text { RH20, and so on). }\end{array}$ \\
\hline $\mathrm{LE}+\mathrm{TE}$ & $\begin{array}{l}\text { Leading edge + trailing edge: the distance between the signal start and the highest } \\
\text { position at which the signal intensity is half of the maximum amplitude (i.e., the } \\
\text { leading edge), and the distance between the signal end and the lowest position at } \\
\text { which the signal intensity is half of the maximum amplitude (i.e., the trailing edge). }\end{array}$ \\
\hline $\mathrm{L} 10+\mathrm{T} 10$ & $\begin{array}{l}\text { Lead } 10+\text { trail10: the distance between the signal start and the position where } 10 \% \\
\text { of the wave form energy (from the signal start) return occurs (lead10), and the } \\
\text { distance between the signal end and the position where } 10 \% \text { of the wave form } \\
\text { energy (from the signal end) return occurs (trail10). }\end{array}$ \\
\hline TI & $\begin{array}{l}\text { Terrain index: the range of ground elevation within } 3 \times 3 \text { digital elevation model } \\
\text { pixels around the GLAS footprint. }\end{array}$ \\
\hline
\end{tabular}

Table 2.

\begin{tabular}{|c|c|c|c|c|c|}
\hline Site & Survey date & $\begin{array}{l}\text { Number } \\
\text { of plots }\end{array}$ & Forest type & $\begin{array}{l}\text { Canopy height } \\
\text { Mean } \pm \sigma(\mathrm{m})\end{array}$ & $\begin{array}{l}\text { AGB } \\
\text { Mean } \pm \sigma \\
\left(\mathrm{Mg} \mathrm{ha}^{-1}\right)\end{array}$ \\
\hline Palangka Raya & 5-6 June, 2013 & 11 & Peat swamp forest & N/A & $169.3 \pm 18.5$ \\
\hline Kg. Ulu Kimanis & 17-18 and 22 June, 2014 & 12 & Secondary forest & & \\
\hline Tenom & 21 June, 2014 & 1 & Secondary forest & & \\
\hline Ulu Tungud & 23-24 June, 2014 & 4 & Forest reserve & $23.8 \pm 3.5$ & $220.4 \pm 43.1$ \\
\hline Sg. Manila & 26-27 June, 2014 & 9 & Oil palm plantation & $4.8 \pm 2.5$ & $48.7 \pm 33.1$ \\
\hline
\end{tabular}


Table 3.

\begin{tabular}{clcc}
\hline Reference & Source data & Forest loss rate $\left(\% \mathrm{y}^{-1}\right)$ & Year range \\
\hline Langner et al., 2007 ${ }^{[50]}$ & MODIS & 1.7 & $2002-2005$ \\
Miettinen et al., 2011 ${ }^{[26]}$ & MODIS & 1.3 & $2000-2010$ \\
Bontemps et al., 2012 ${ }^{[53]}$ & SPOT/Vegetation & $1.3-2.7$ & $2000-2008$ \\
Hansen et al., 2013 ${ }^{[24]}$ & Landsat & 1.1 & $2000-2012$ \\
Malaysian Borneo & Landsat & 1.2 & $2000-2012$ \\
Indonesian Borneo & Landsat & 1.0 & $2000-2012$ \\
This study & ICESat/GLAS & $\mathbf{2 . 4}$ & $2004-2007$ \\
Malaysian Borneo & ICESat/GLAS & 1.4 & $2004-2007$ \\
Indonesian Borneo & ICESat/GLAS & $\mathbf{2 . 9}$ & $2004-2007$ \\
\hline
\end{tabular}

Table 4.

\begin{tabular}{llc}
\hline \multicolumn{1}{c}{ Reference } & \multicolumn{1}{c}{ Source data } & Total AGB (Gt) \\
\hline Miettinen et al., 2009 ${ }^{[57]}$ & MODIS & 11.988 \\
Saatchi et al., 2011 ${ }^{[17]}$ & MODIS, ICESat/GLAS & 14.86 \\
Baccini et al., 2012 ${ }^{[22]}$ & MODIS, ICESat/GLAS & 11.68 \\
This study & ICESat/GLAS & $\mathbf{1 0 . 3 4}$ \\
\hline
\end{tabular}


Figure 1

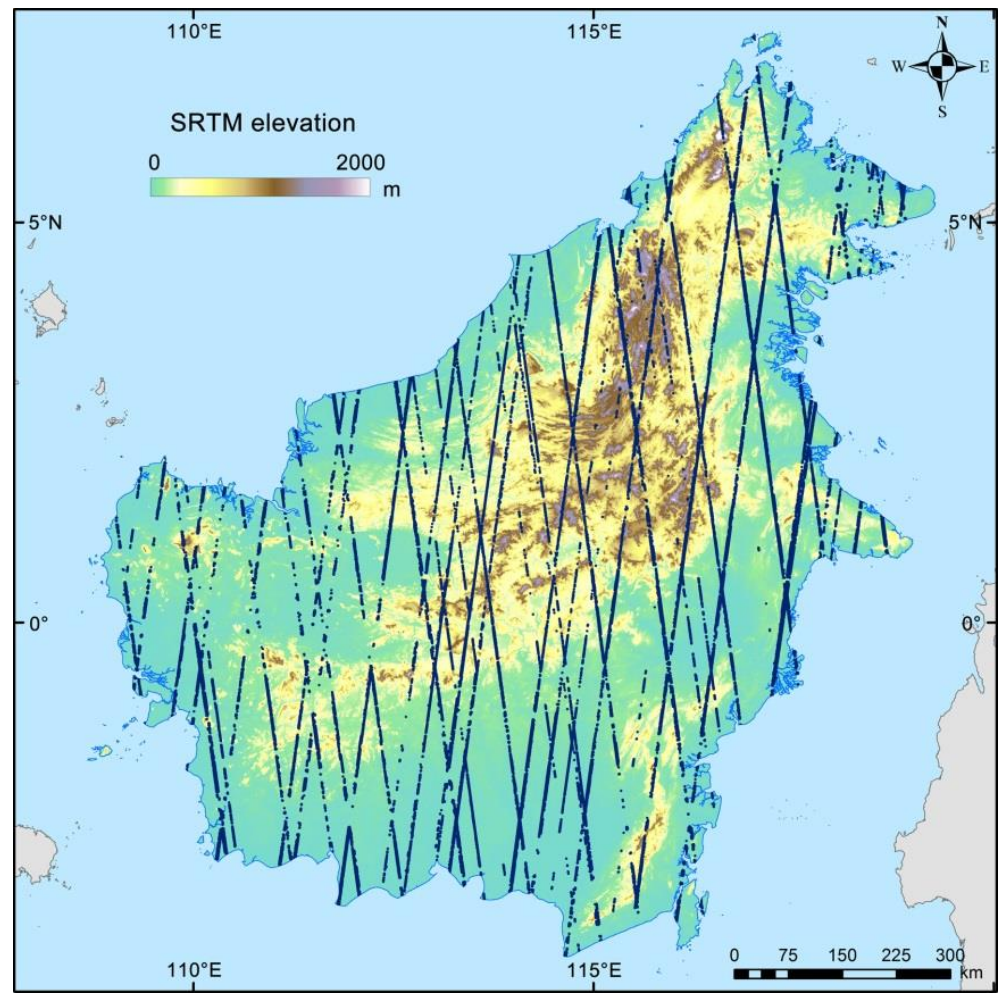


Figure 2

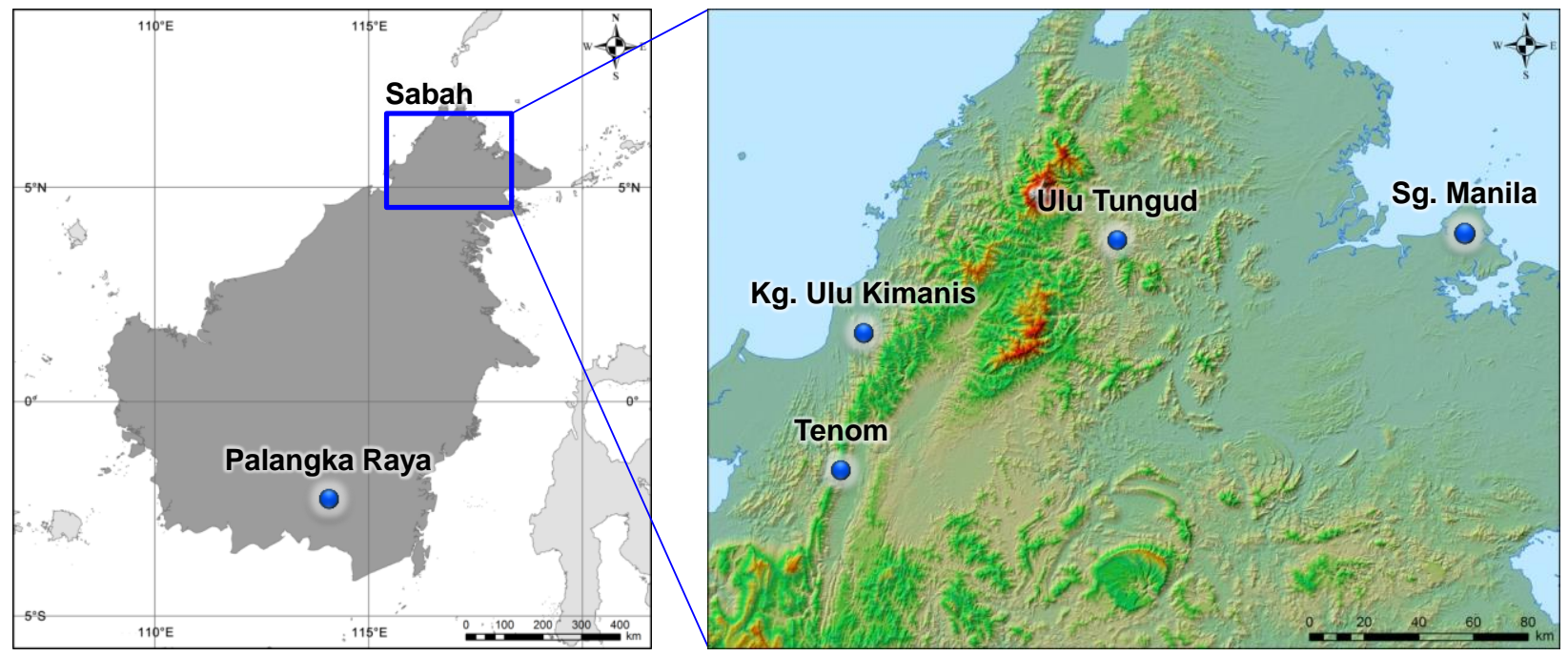


Figure 3

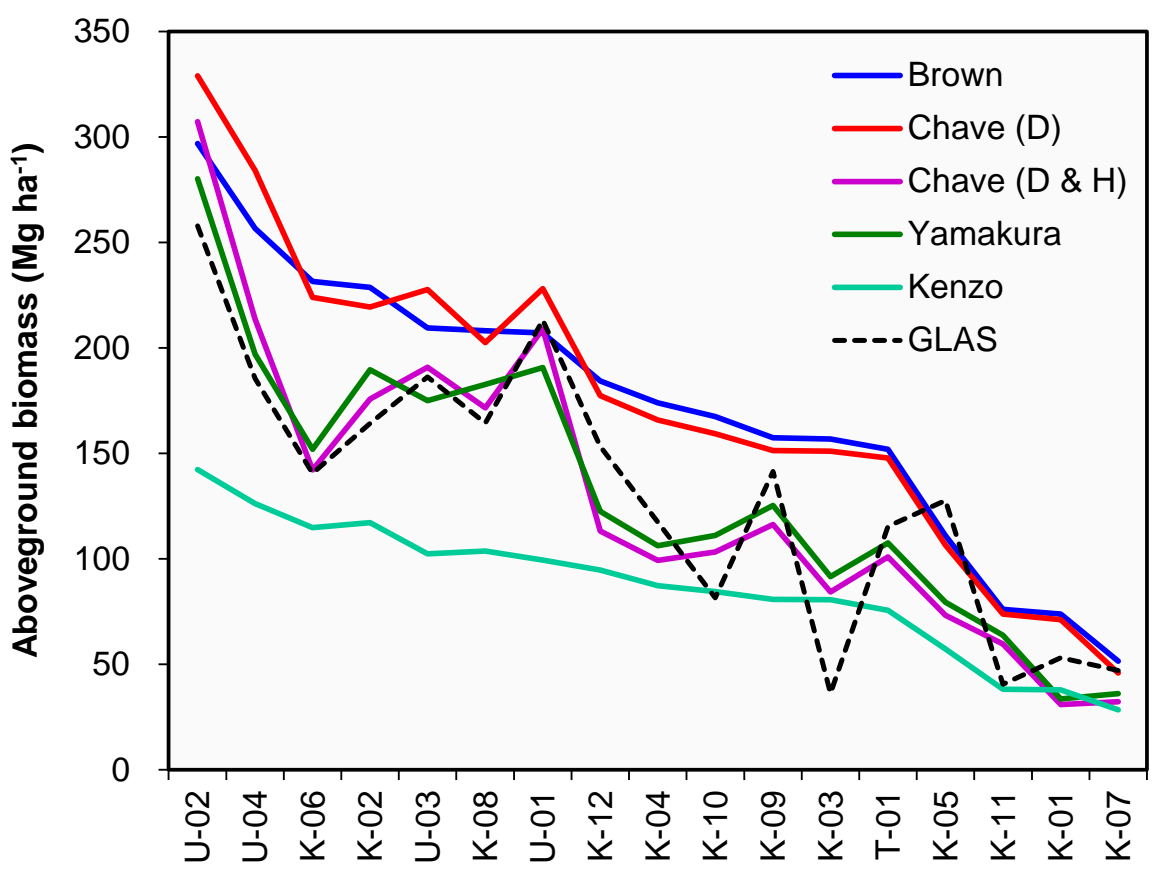


Figure 4

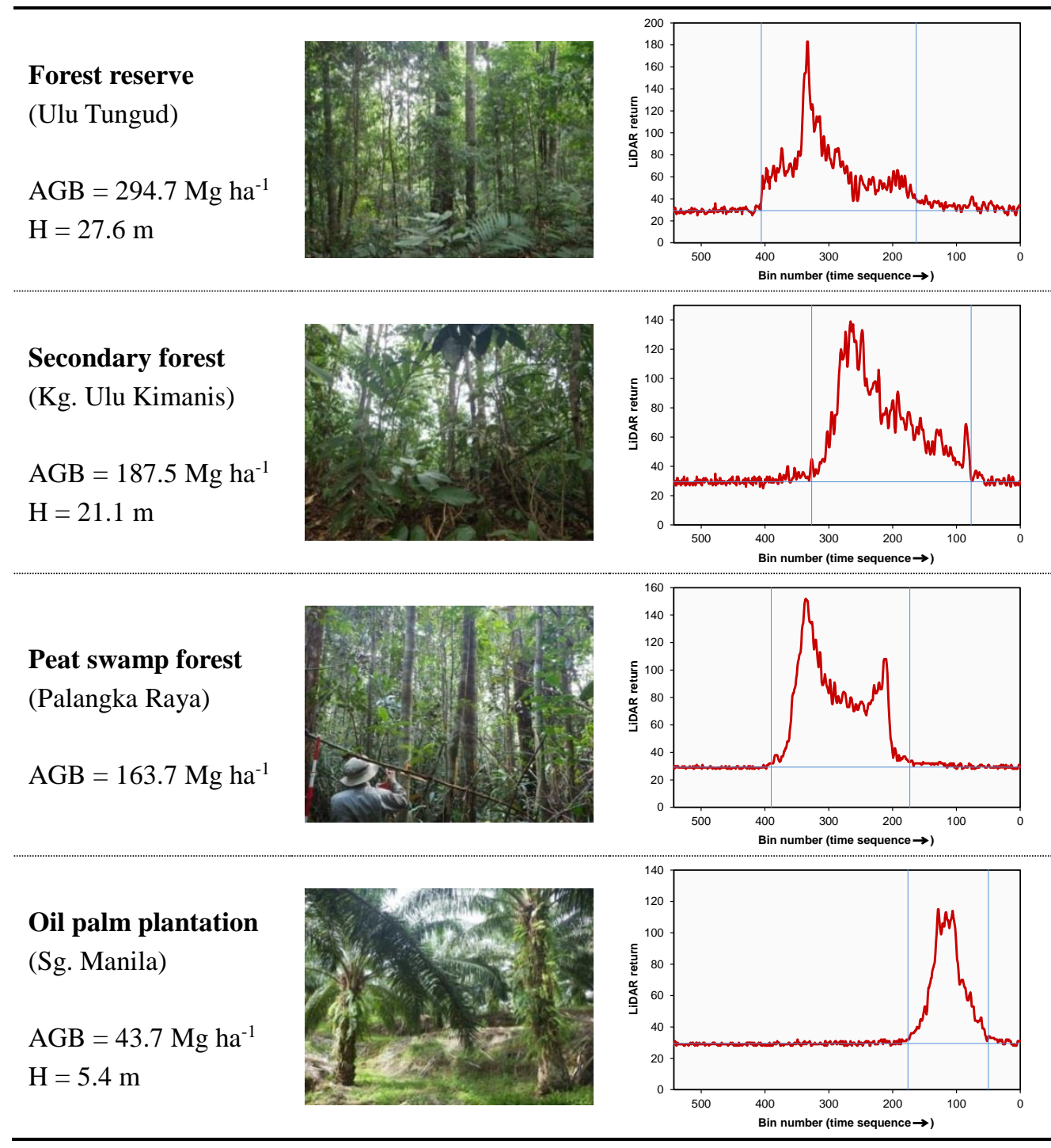


Figure 5

(a)

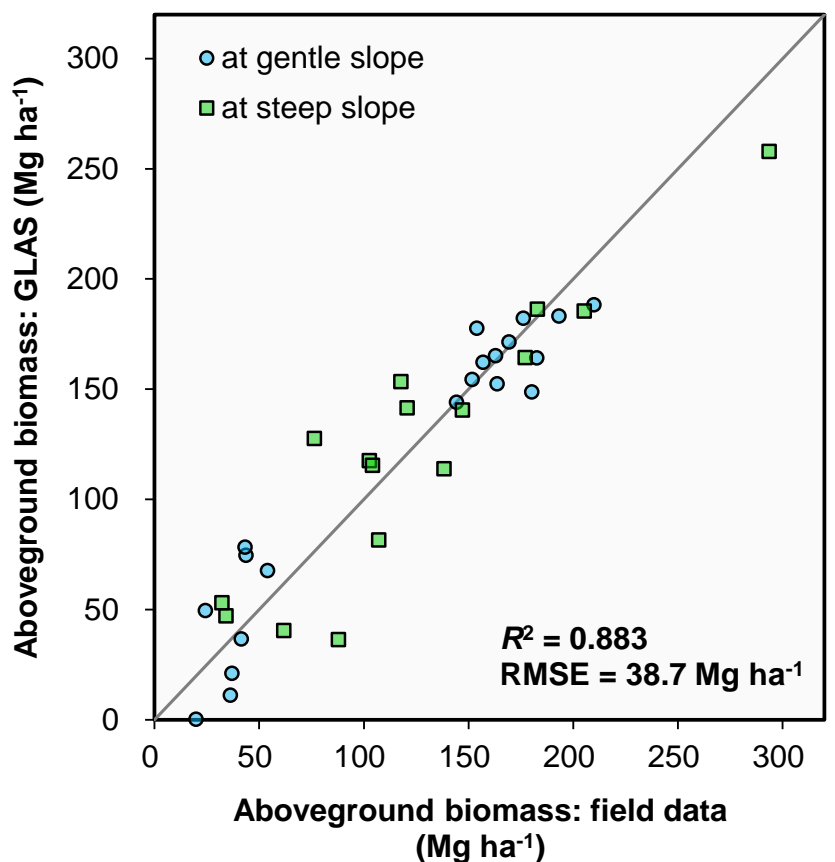

(b)

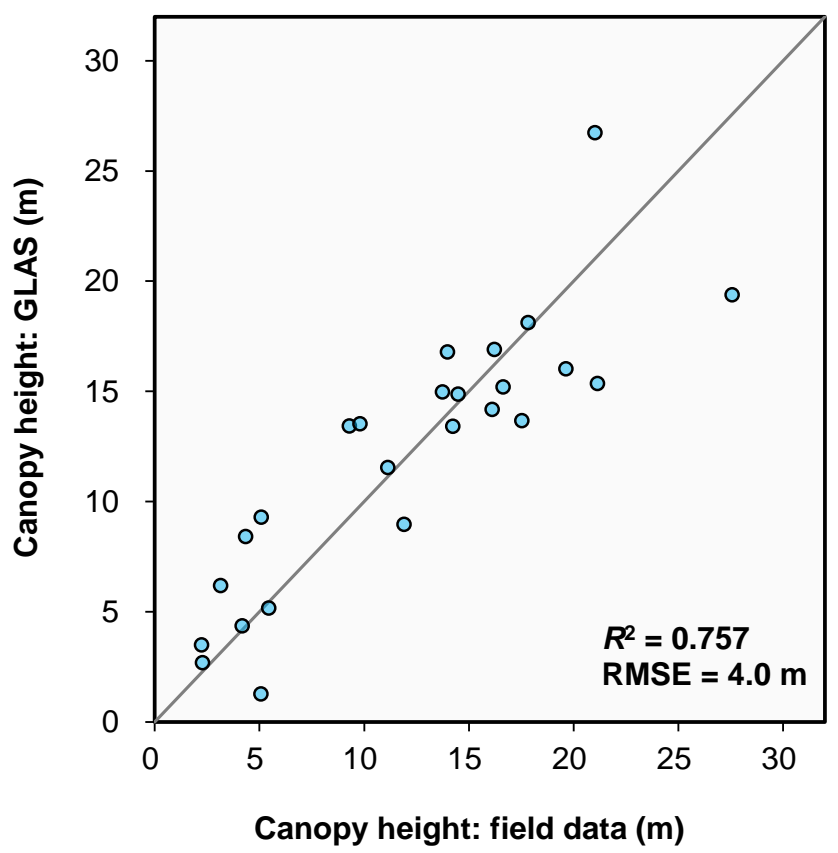


Figure 6

(a)

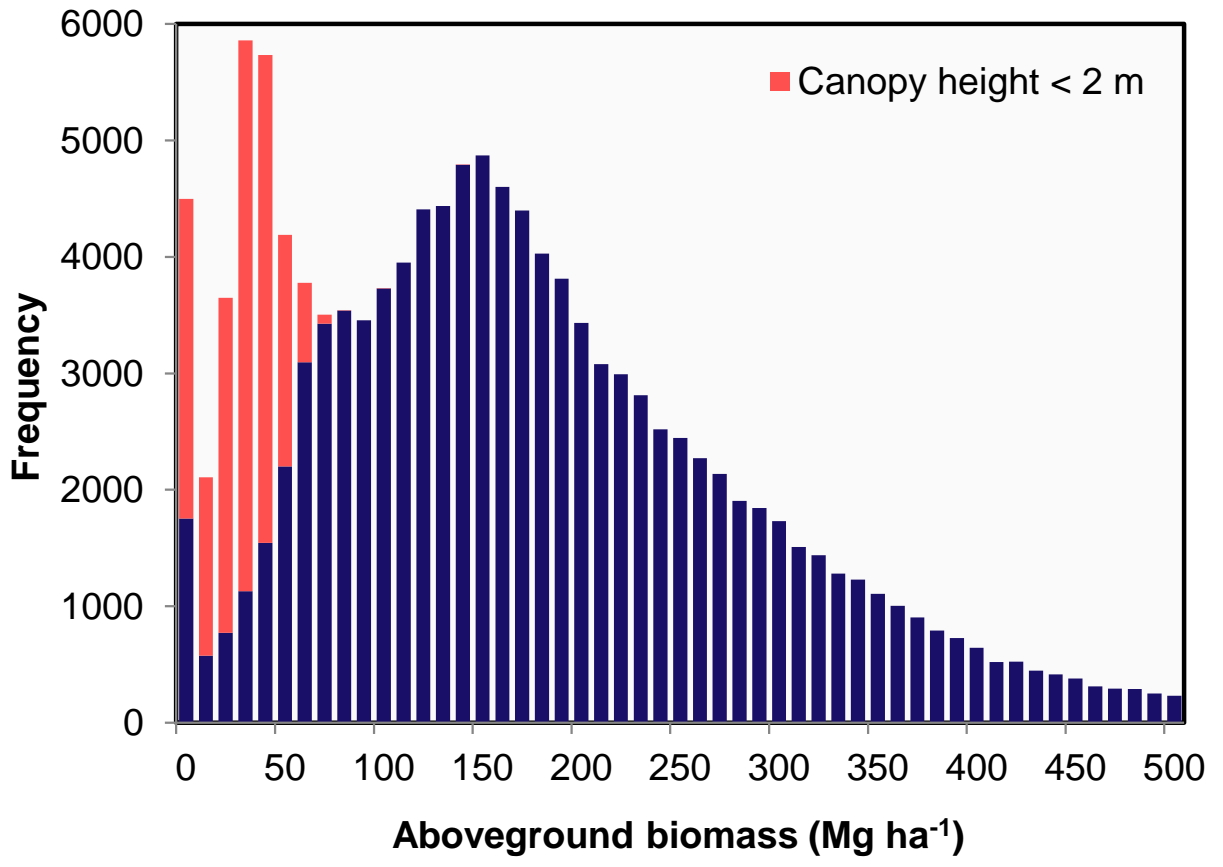

(b)

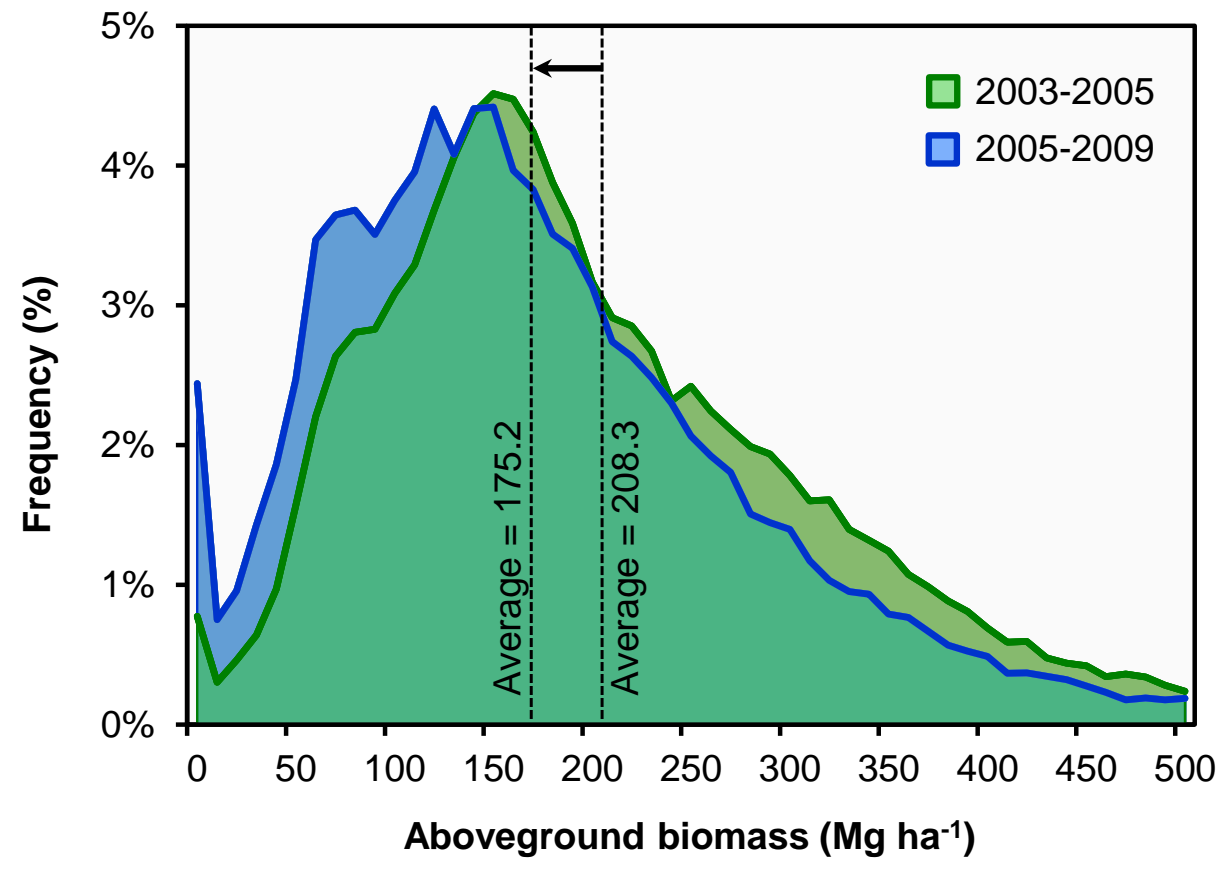


Figure 7

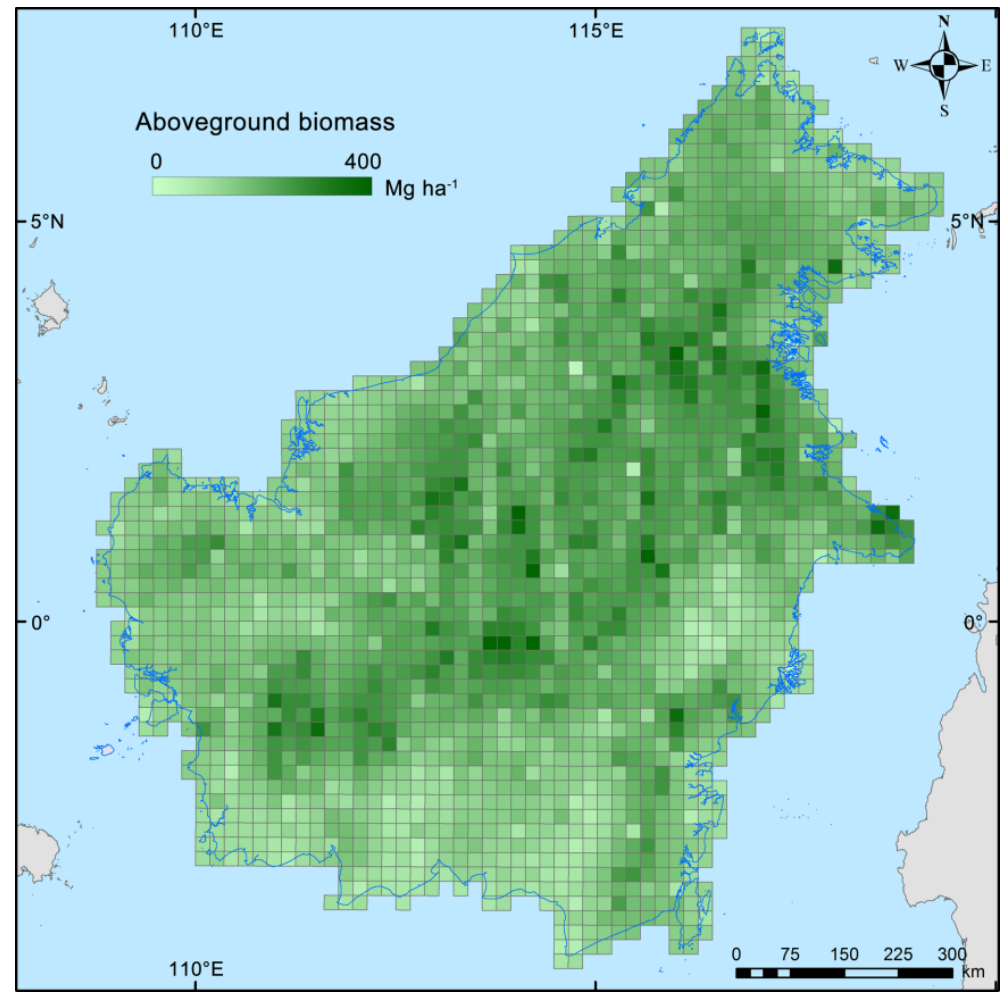

